\title{
What is your diagnosis?
}

\section{Case}

A 27-year-old G2 P1 woman at 20 weeks 3 days of gestation by her last menstrual period was referred to our clinic with an abnormal result in the four chamber view at obstetric ultrasonographic evaluation. At our clinic, detailed fetal ultrasonographic cardiac examination was performed (Figure 1). In order to detect the associated fetal abnormalities, a detailed ultrasonography was made and amniocentesis was performed simultaneously. These investigations of the fetus were otherwise unremarkable. What is your diagnosis?

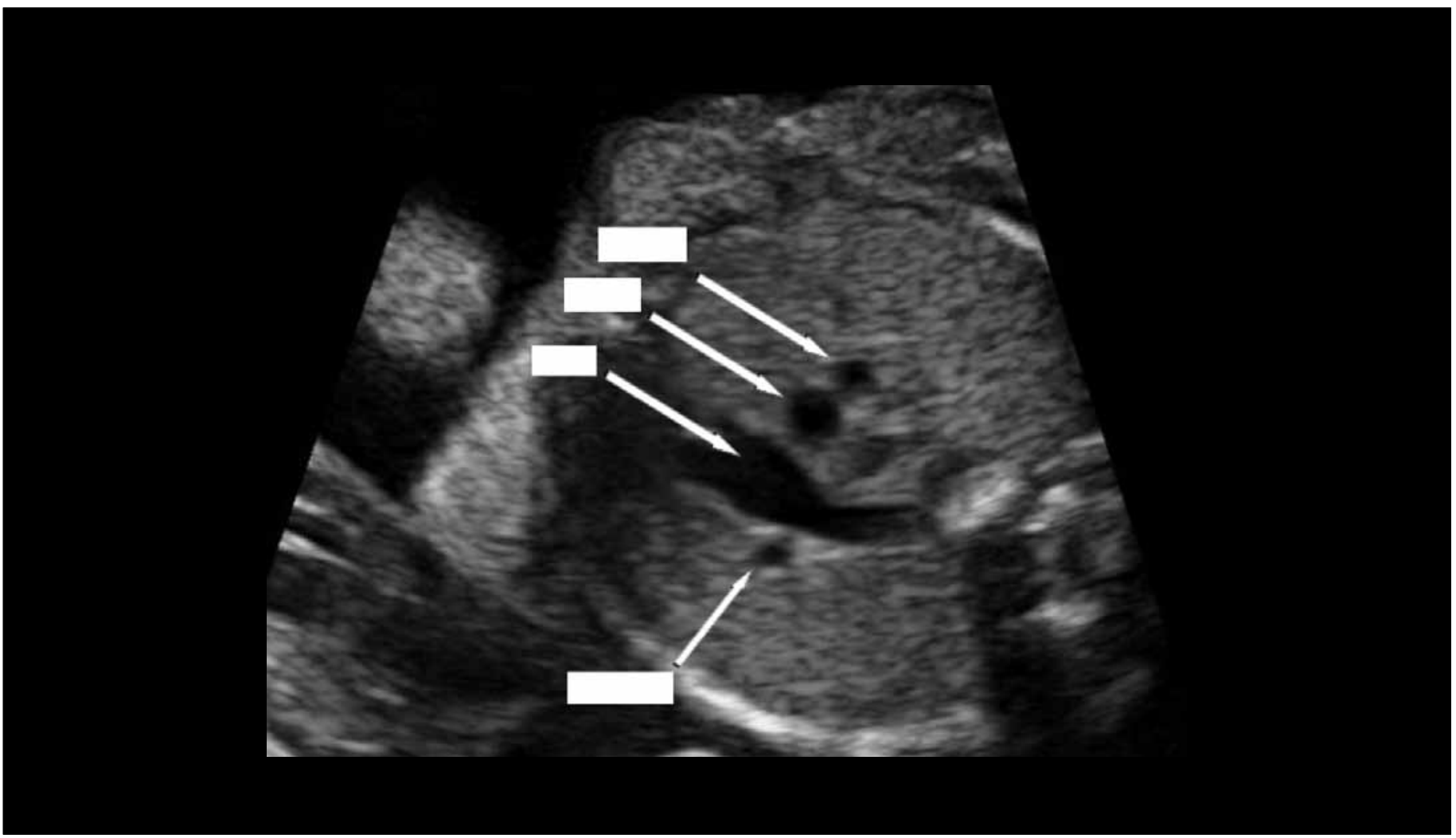

Figure 1. Fetal heart USG 


\section{Answer}

Detailed fetal ultrasonographic cardiac examination showed dilated coronary sinus and PLSVC was determined on the supernumerary vessel to the left of the pulmonary trunk (Figure 2).

Persistent left superior vena cava (PLSVC) represents the most common form of anomalous systemic venous return in adults. It has been observed in $0.3 \%$ of autopsies in the general population and in $4-8 \%$ of patients with congenital heart disease (CHD) (1).

PLSVC should be considered in case of detection of extra vessel on the left side and the coronary sinus dilatation at the pulmo-

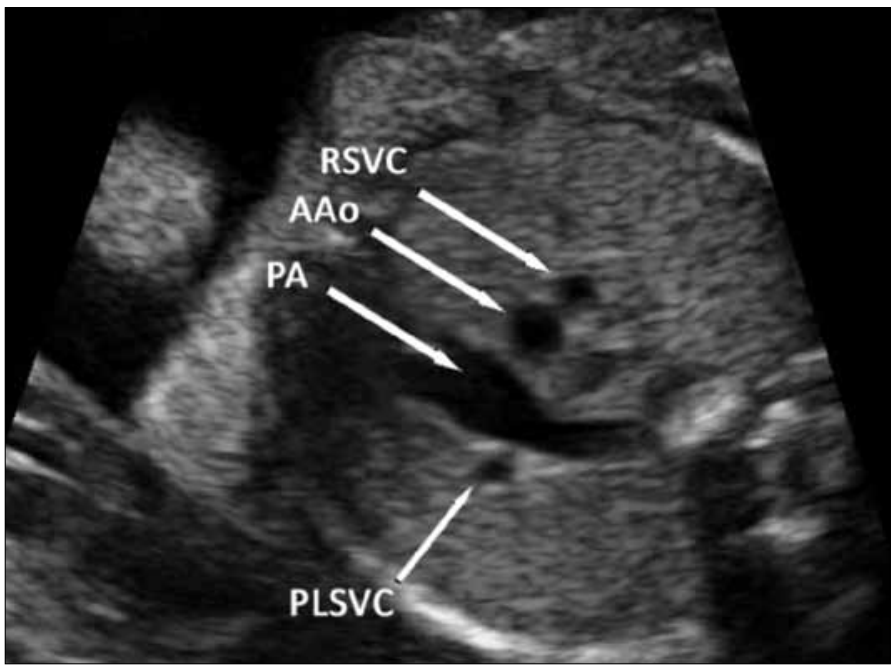

Figure 2. Abnormal three-vessel view. Persistent left superior vena cava (PLSVC) near right ventricule outflow tract at three vessels section. PA, pulmonary artery, AAo, ascending aorta, RSVC, right superior vena cava

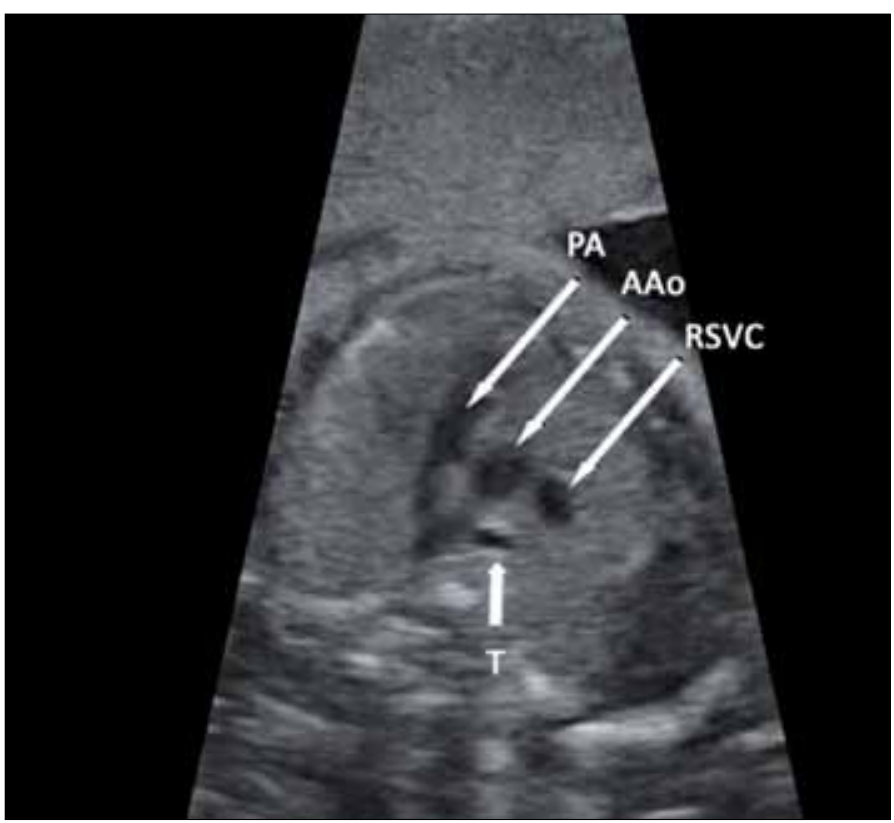

Figure 3. Normal three-vessel view. PA, pulmonary artery, AAo, ascending aorta, RSVC, right superior vena cava, $\mathrm{T}$, trachea nary artery outflow cross-section (cross-section of three-vessel) during obstetric sonography (1).

After diagnosis of PLSVC; fetal echocardiography, karyotype analysis, and ultrasonographic assessment of fetal anatomy should be made.

The prevalence of PLSVC in the fetal population remains uncertain. Under normal conditions, the coronary has a diameter of 1 to $3 \mathrm{~mm}$, courses perpendiculer to interatrial septum. In the presence of PLSVC, the coronary sinus is dilated and measures between 3 and $7 \mathrm{~mm}$.

The three-vessel view is a transverse view of the fetal upper mediastinum is as simple to obtain as the four-chamber view. It demonstrates the main pulmonary artery, ascending aorta and superior vena cava in cross- or oblique sections (Figure 3).

PLSVC was diagnosed in the presence of an abnormal threevessel view showing a supernumerary vessel to the left of the pulmonary trunk (2). The diagnosis was then confirmed in the long-axis view, demonstrating by color Doppler direct or indirect drainage via the coronary sinus into the left or right atrium. The importance of a PLSVC lies in a greater prevalence of associated CHD. PLSVC occurs in up to $3-8 \%$ of patients with CHD, making PLSVC the most common venous anomaly associated with CHD (3). Additionally chromosomal anomalies were reported in $9 \%$ of PLSVC(4).

During the early development the cephalic portion of the embryo, fetal venous blood is drained by bilateral symmetrical right and left anterior cardinal veins. The development of the left innominate vein that bridges the anterior cardinal veins at 7-8 weeks gestation is followed by atrophy of the left anterior cardinal vein. A small portion remains as the left superior intercostal vein and the distal part gives rise to the coronary sinus (5).

To gether with a concomitant dilated coronary sinus, PLSVC can be detected at three vessels view of the right ventricule outflow tract (Figure 1). These findings must be examined for cardiac (heterotaxy, ventricular septal defect ve coarctation of aorta) and noncardiac abnormalities $(4,6,7)$. In our case, there was no extra cardiac or noncardiac abnormalities. The chromosome analysis of the fetus revealed a normal caryotype.

With all these findings, our definitive diagnosis was isolated PLSVC. Isolated PLSVC cases have been reported to cause no adverse abnormalities either at early neonatal period or at adulthood (1).

All this information was given to family and the pregnancy was followed up.

Three-vessel cross-section is a crucial view for antenatal obstetric ultrasonography during cardiac examination.

At this section in the presence of an extra blood vessels next to the pulmonary trunk and dilated coronary sinus PLSVC should be considered.

Oktay Kaymak, Serkan Kahyaoğlu, Şebnem Şen Özyer, Şevki Çelen, Nuri Danışman

Clinic of Perinatology, Dr. Zekai Tahir Women's Health Training and Research Hospital, Ankara, Turkey 


\section{References}

1. Galindo A, Gutiérrez-Larraya F, Escribano D, Arbues J, Velasco JM. Clinical significance of persistent left superior vena cava diagnosed in fetal life. Ultrasound Obstet Gynecol 2007; 30: 152-61. [CrossRef]

2. Yoo SJ, Lee YH, Kim ES, Ryu HM, Kim MY, Choi HK, et al. Threevessel view of the fetal upper mediastinum: an easy means of detecting abnormalities of the ventricular outflow tracts and great arteries during obstetric screening. Ultrasound Obstet Gynecol 1997; 9: 173-82. [CrossRef]

3. Berg C, Knüppel M, Geipel A, Kohl T, Krapp M, Knöpfle G, et al. Prenatal diagnosis of persistent left superior vena cava and its associated congenital anomalies. Ultrasound Obstet Gynecol 2006; 27: 274-80. [CrossRef]
4. Pasquini L, Fichera A, Tan T, Ho SY, Gardiner H. Left superior caval vein: a powerful indicator of fetal coarctation. Heart 2005; 91 : 539-40. [CrossRef]

5. Nsah EN, Moore GW, Hutchins GM. Pathogenesis of persistent left superior vena cava with a coronary sinus connection. Pediatr Pathol 1991; 11: 261-9. [CrossRef]

6. Machevin-Surugue E, David N, Verspyck E, Labadie G, Blaysat G, Durand I, et al. Dilated coronary sinus in prenatal echocardiography; identification, associations and outcome. Prenat Diagn 2002; 22: 898-902. [CrossRef]

7. Chaoui R, Heling KS, Kalache KD. Caliber of the coronary sinus in fetuses with cardiac defects with and without left persistent superior vena cava and in growth-restricted fetuses with heart-sparing effect. Prenat Diagn 2003; 23: 552-7. [CrossRef]

\section{ADVISORY BOARD OF THIS ISSUE (March 2013)}

Ayla Günlemez
Aysel Derbent
Aysun Altınok Karabulut
Banu Dane
Batuhan Özmen
Beril Yüksel
Berna Haliloğlu

Ayla Günlemez

Cem Atabekoğlu

Eray Calıskan

Evrim Erdemoğlu

Gazi Ylldırm

Ibrahim Esinler

Kubilay Ertan

M. Murat Naki

$\begin{array}{ll}\text { Mehmet Harma } & \text { Yalcin Kimya } \\ \text { Murat Ekin } & \text { Yaprak Engin Üstün } \\ \text { Mutlu Meydanlı } & \text { Yusuf Üstün } \\ \text { Oluş Api } & \text { Zehra Kurdoğlu } \\ \text { Selçuk Ayas } & \\ \text { Talat Umut Kutlu Dilek } & \\ \text { Utku Nasuh Doğan } & \end{array}$

